\title{
Children's Construction of Identity in Virtual Play Worlds - A Classroom Perspective
}

\author{
ANNE BURKE \\ Memorial University
}

Abstract

The formation of identity is inextricably linked to powerful meaning-makers in a child's young life. In the $21^{\text {st }}$ century, this typically involves engagement in virtual play worlds. This case study reports on the identity construction of young gamers in a classroom as perceived through an I/identity framework (Rowsell \& Abrams, 2011), associative I/identity framework (Abrams, 2011) and informed by New Literacies through a socio-cultural lens. Children engage in Discourses (Gee, 2007; 2008; 2009) to experiment with early rehearsals and re-enactments, navigating fluidly among different roles and virtual world experiences. This study shows how children form affinity groups and social connections with other players in their real world play spaces and online, thus creating a meaningful interplay of their real world and virtual I/identities in a variety of ways.

\section{The $21^{\text {st }}$ Century Playground}

Jackson cries out to Ethan as he gets on the bus "See you at the April Fool's party tonight". Ethan waves back in response. The classroom teacher looks to Ethan, who explains, "On Club Penguin, Miss, it's the party of the year".

Field Notes, April 2011

As learning fluidly moves across multimodal spaces, as represented in the playground of the $21^{\text {st }}$ century, the experiences of young children extend across both virtual play worlds and school-yard playgrounds. Mediated through the types of role-play and playmaking found in these spaces, their identities have ultimately come to shape their social and cultural lives. "Young children are "gadgeted," and opportunities to learn from digital media abound" (Blanchard \& Moore, 2010, p. 2). Popular online virtual play worlds such as Club Penguin, Moshi Monsters, and Webkinz, to name just a few, are becoming the new playgrounds for children of the $21^{\text {st }}$ century. In this study, I examine what it means for children to be "meaning makers" across a number of play spaces. The lives of children in the $21^{\text {st }}$ century are quite different from the childhood of their parents and teachers. Parents and teachers of earlier generations would scaffold and engage children as active participants in constructing their own knowledge mainly through imaginative and dramatic play (Vygotsky, 1978). In the $21^{\text {st }}$ century, however, much of children's play construction is supported by media and interaction on virtual world play sites.

In this article, I focus in on Disney's Club Penguin, an intricate virtual world aimed at primary and elementary school children. In this virtual world, children can assume the identities of penguin avatars, and engage in various games and activities. Similar to other large virtual sites such as Webkinz and Moshi Monsters, Club Penguin offers opportunities for social networking and gaming at different membership levels. Simple entry level onto the site requires a parent's e-mail registration, and provides the child with a penguin avatar and an igloo. Deluxe memberships, which can be purchased, provide children with special 
privileges such as access to costumes for their penguins, as well as theme parties and virtual merchandise to outfit their virtual igloo. The virtual site provides a winter wonderland, where children play a number of activities, and socialize in spaces such as the pizzeria or the dance club. The very essence of children's understanding as "meaning makers" in their world, stems from the social events characterized in their lives through play (Wells, 1999). Therefore, the virtual social events involved in the Club Penguin game-play are significant, because the rich social interactions found through play create opportunities for children to experiment with early rehearsals and re-enactments of roles and experiences.

With the growing popularity of virtual play spaces such as Club Penguin, and the new age appeal of virtual rehearsals and re-enactments, there has emerged a new landscape for play and learning. Through the medium of virtual play, then, new realms and possibilities emerge. Within the new realms, I examine the constructed identities of children's play-lives across both online and offline play spaces, while considering the characteristics of Abrams' (2011) associative identity: their purposeful behaviors, their motivations through projective identities, the fluidity between their projective online and performed offline identities, and the leverage gained through accomplished game play.

\section{The Changing Nature of Play in the Virtual World}

The nature of children's play has changed drastically over the past decade, and its definition has expanded to include digital media. Lauwert (2009) takes an in-depth look at the geographies of children's play, and notes that in recent years there has been a "'transformation from a one-to-many to many-to-many geography of play' which 'largely coincides with a shift from non-digital to digital or digitalized geographies of play"' (p. 67) and "the many-to-many model has gained in force and importance due to technological innovations that facilitate easy contact and exchange between users" (p. 67). In drastically changing the nature of toys and play, wide access to these new technologies has contributed to a rapidly evolving notion of play in children's worlds.

Media and digital toys have infiltrated the homes of both developed and developing nations. The effects of changes in the digital world bear indeterminate consequences for children from different languages and cultures. "Since cultural and language norms in many developing and least-developed nations differ markedly from Western norms, it is possible that digital media may affect emergent literacy skills in these nations in ways that cannot be foreseen" (Blanchard \& Moore, 2010, p. 3). Consequently, a new explicit focus for digital toys is the development of literacy skills alongside increase in the use of social networks: "there has been an increase in 5-7s use of social networking weekly ... from 7\% in 2009 to $23 \%$ in 2010, although this relates to them visiting virtual worlds like Club Penguin or Moshi Monsters rather than mainstream social networking sites" (Ofcom, 2011). Also, "More than a third (38\%) of all children between the ages of 0-8 have ever used a cell phone, iPod, iPad or similar device to play games, use apps, or watch videos, TV shows, or movies; but by the time they're in the 5-to-8-year-old range, half (52\%) have done so at one point or another" (Common Sense Media, 2011, p. 21).

In her study, Marsh (2009) explores how literacy skills are integral to the young gamers playing Club Penguin. She states that, "literacy can be seen as a key aspect of the online interaction rituals that create a recognizable interaction order for the users of Club Penguin" (Marsh, 2009, p. 5). Also, "text is kept to a minimum throughout the virtual environment and is used primarily to identify the use of buildings. Symbols, such as arrows, 
are used throughout the world to guide penguins" and "this limited use of text and extensive use of icons and symbols means that very young children find it relatively straightforward to navigate Club Penguin" (Marsh, 2009, p. 6). She argues that "literacy [is] central to Club Penguin" (Marsh, 2009, p. 9), and as users recognize and repeat a familiar order of interactions, they develop literacy within the game.

In modern times, play has become more and more digitized, and there is a large focus on the emerging literacy skills of the younger population. In her study of Webkinz, Cowan (2010) found that parents of the children in her study "applauded games on the site that teach typing skills and the emphasis on responsibility inherent in caring for pets and purchasing necessities" (p. 37). Further to this, she contends that "education is somewhat behind the times" in implementing a more technological approach to learning and "most schoolmediated technology platforms do not comfortably support virtual sites" (Cowan, 2010, p. 44).

In Black's (2010) study of Webkinz, she notes that the "Webkinz world offers children a unique opportunity for immersion in literacy rich and academically-oriented practices that may enhance those that are readily available in their daily lives" (p. 19). Play in classrooms and on playgrounds provides children with opportunities to explore social roles, language, and ways of being. Within virtual worlds, however, there are also more foundational opportunities to mediate literacy and identity through early rehearsals and virtual character re-enactments.

As children play video games, aspects of their real world and virtual identities interact and learning takes place. Consalvo (2003) suggests that many game fans will go to great lengths to immerse themselves in digital worlds, often creating detail, suspense, character development, reader identification and a strong attachment to a main character. A young gamer's real world identity is "a nonvirtual person playing a computer game" (p.50), and their virtual identity is their "virtual character in a virtual world" (Gee, 2007, p.49). A child's virtual identity is both inhibited and enabled by a multiplicity of identities: the real world, the performed, the projective and the associative identities. Their real world identity is informed by their natural identity, by Discourses, institutional identity (identity pronounced by laws) and affinity identity (identity formed by social groups). According to Gee (2007), one's projective identity is signified by "values and desires [that students project] onto the virtual character" (p. 50). It also entails "seeing the virtual character as one's own project in the making" (p. 50). In this projective identity, students use personal aspects of their lives, their history, and some attempt to compensate for limitations in their real world characteristics. Gee contends that, "if learners are to take on projective identities . . they must come to project their own values and desires onto the virtual identity" (p. 62). The formation of identity is an intricate process, and Turkle (2011) describes the identity exploration work in making an avatar or a profile as "a statement not only about who you are but who you want to be" (p. 180) or as a performance piece where personal and exploration can take place. Likewise, Apperley (2010) explains that game play cannot be understood as merely an event that takes play on an isolated digital screen: "The concept of situations is important because it articulates the overlapping connection between digital gaming and offline activities, and how game-play experiences are shaped by everyday life" (p. 120).

According to Jenkins (2005) educators should harness this intense interest of video game playing and seek to develop a curriculum that compliments and collaborates with what the youth are interested in. "The educational use of electronic simulation games works ... not 
as a replacement for good teaching or tried-and-true methods, but as a tool that good teachers can use to spark learning and to provide a context for a range of other related experiences" (Jenkins, 2005, p. 51).

Gee's (2007) recommendation to teachers is to exercise prudence, choosing and using virtual reality worlds carefully in their classroom. As students adopt virtual features and interact with virtual conditions through their projective identities while playing video games, they will rehearse "new values and ways of being in the world bases by powerful juxtaposition of their real-world identities" (p. 63). In addition to the learning inherent in projective identity play, students' learning experiences can be greatly enhanced by virtual worlds because they are designed to give students a practical learning experience. This learning, which involves adopting new identities and providing students with new choices, should also entail creating new opportunities for students to mediate through their older and newer identities. Gee contends that good video games offer students a greater potential to learn because they provide rewards based upon problem solving skills and higher order thinking, and students must learn and absorb these as they advance in the game. These values are not necessarily recognized by the education system; "educators often bemoan the fact that video games are compelling and school is not" (Gee, 2007, p. 65). Unfortunately, many teachers accept this as the norm. What needs to be understood is how video games entice children to guide their own learning through play.

Social identity is defined as the "values, established practices, knowledge and skills" (Gee, 2008, p.23) that people develop through interacting with others. A child using video games engages in social interactions both as a virtual identity within the game and as a real world identity among other players. "Gamers often organize themselves into communities of practice and that creates social identities with distinctive ways of talking, interpreting experiences, and applying values, knowledge and skill to achieve goals and solve problems" (p. 24). Videogames are designed to connect with gamers' specific identity, their characteristic goals and norms.

To understand how game play has changed, and what this means for children and the construction of their literate lives and identity, I use the theoretical frameworks of New Literacies with a focus on Discourses (Gee, 2007; 2008; 2009), and I/ identity (Rowsell \& Abrams, 2011; Abrams, 2011).

\section{Theoretical Framework: New Literacies, Discourses, and Identity}

New Literacies, the inevitable companion to digital media, constitute a growing body of literacy research focused around digital media. Newer literacies or digital media are a result of the exponential growth and pervasiveness of technology. During the past decade this has resulted in a parallel growth of communication in textual forms and cultural practices. New literacies are more "participatory, collaborative and distributed in nature than conventional literacies" (Lankshear and Knobel, 2006 p. 9). The expanded field of research in children's play and virtual worlds (Black, 2010; Burke, 2010; Burke, 2013, Burke \& Marsh, 201; Carrington, 2003; Carrington \& Hodgetts, 2010; Marsh 2010; Zevenbergen, 2007 ) in this area reveals an understanding of the changes in children's play and textual practices, changes that are mediated by digital technologies.

An intricate discussion of identity in Leander and Frank (2006) focuses the connection between social and cultural worlds. Another prospective way of envisioning this relationship of identity and literacy is to envision the individual as an active agent in the 
development of their literate and social practices. Many researchers consider this shift in emphasis to be resultant of a larger movement away from a more traditional, skills-based conception of literacy. The traditional view of literacy frames the literate practices of an individual as separate from certain motivating factors, such as their individual interests and social practices, which in this study would be a child's virtual world interactions. These researchers explain, however, that "the social turn in literacy theory and research (Gee, 1994) over the last three decades has generated close, in-depth research on the literacy practices of actual people, a move that has turned researchers' and theorists' attentions to the roles of texts and literacy practices as tools or media for constructing, narrating, mediating, enacting, performing, enlisting, or exploring identities" (Moje \& Luke, 2009, p. 416). Put another way, researchers and theorists are now able to interrogate the reciprocal manner in which identity both mediates and is mediated by textual engagement of children's constructed identity in virtual worlds, as is the case in this study.

Identity construction is a fluid process that builds on literate practices and events, including social networking. Found within these literate practices are Discourses. Discourse focuses on how people get recognized as social beings. Recognition is a fluid process, and it changes based on the role a person is participating in at a particular time. For example, when projecting a socially-situated identity, people have to demonstrate who they are and what they are doing. Therefore, being in a Discourse also shapes identity, as one needs to be able to negotiate a "dance with words, deeds, values, feelings, other people, objects, tools, technologies, places and time so as to get recognized as a distinctive sort of who [emphasis added] doing a distinctive sort of what [emphasis added]" (p. 7). As we use Discourses we navigate between different selves. Whereas discourse (with lowercase "d") signifies "language in use" (Gee, 2009, p.6), a Discourse (with capital "D") refers to the enactment and recognition of socially situated identities or 'kinds of people' (Gee, 2009). Our primary Discourse equips us with our sense of self and "sets the foundation of our cultural specific vernacular language" (Gee, 2009, p. 11). This is the language we use commonly, our dialect, and it represents our life-worlds. In contrast, our secondary Discourses are identities that we acquire from primary institutions such as church and schools. Unfortunately, for some students, primary discourses are at odds with school discourses, creating potential disconnects with their schooled learning. Gee proposes that "the issue of academic language is another place where a focus solely on language is inadequate" (p.16). Looking closely at video games use of "lucidly functional language" is easily understood because it is "always associated with actions, goals, experiences, image and dialogue" (Gee, 2009, p. 23).

Building on Gee's work, Abrams (2011) theorizes about the association between a young gamer's real world values and how these affect the virtual character. She analyzes and deconstructs the "inter-textuality to help to explain the behavior of gamers in relation to their virtual enactments" (Abrams, 2011, p. 227). In essence, Abrams (2011) argues that all virtual personas have an associative identity, which is created through their emotional and social connections to their virtual identity. To explore this idea, Abrams adopts Rowsell and Abrams' (2011) concept that I/identity signifies both one's distinct ways of being and situated practices ('big I' Identity) as well as physio-emotional responses ('little i' identity)" (p.221). Bridging to Gee's $(2001,2008,2011)$ conception of D/discourse, this associative concept of I/identity speaks to acquired knowledge, sense of self, and one's specific behaviors, contending that one's identity is shaped by both social expectations and funds of knowledge, which empower individuals with a sense of agency. A gamers' I/identity, 
therefore, is "situated ways of being and physio-emotional responses are directly linked to what is happening both on and off the screen" (Abrams, 2011, p. 234).

The associative state entails aspects of performed identity and projective identity. A performed identity involves "deliberately behaving in a way that conveys a desired image, personality, or status" (Abrams, 2011, p. 227). Inherent in this concept are the recognition of and reproduction of stereotypical behaviors, which are attributed to a particular character. Another aspect of an associative state is Gee's (2007) concept of the projective identity: "one's responsibility for and connection to a virtual character" (p. 223). The significance of the performed and projective aspects of associative I/identity is the "porosity" (Gee, 2007, p. 223) between on-screen and off-screen identities, where one may absorb aspects of the other. There is fluidity between them charged by emotions that allow a real world person to identify with a virtual character. For Abrams (2011), capturing this association between them "is tied to one's socially situated practice, but also affect[s] one's sense of self in relation to the game" (p. 228). This associative I/identity "highlights the interconnection between the performed identity and projective identities" (Abrams, 2011, p. 236) and accounts for a player's experiences and changes in behavior while interacting with virtual activities.

Three things are required for associative identity and meaning-making to take place: (a) feeling connected to the virtual character, (b) being knowledgeable of the gaming environment, and (c) internalizing game characteristics. When a gamer is engaged in the associative state, it represents the "verbal and physical responses that show his/her association of the real with the virtual and the virtual with the real" (Abrams, 2011, p. 235). The gamer may also be observed, "responding to virtual stimuli in an effort to achieve social and/ or emotional gains related to the performed identity" (Abrams, 2011, p.235), to get a response from their audience. In this way, gamers are able to "conceptualize meaning through an embodied experience" (Abrams, 2011, p. 239), and this experience, combined with the performed and projective identity, allows students to "find personal reward in their adoption of game-specific Discourse" (Abrams, 2011, p. 239). In summary, Abrams' associative I/identity theory suggests that when players, who possess facility within the virtual gaming environment, reference their social expectations and real life funds of knowledge as they perform and project a virtual identity, they will draw emotional connections and internalize the game, creating a meaningful interplay of their real world and virtual I/identities.

\section{Methodology}

This socio-cultural, qualitative research encompasses descriptive case studies (Stake, 1995; Merriam, 1998), participant observation (Erickson, 1984), focus groups (Hoppe, 1995), as well as side shadowing and interviews (McClay, 2002; Rowsell \& Burke, 2009) with individual children at two urban schools and one after-school centre, over a period of three years. For this study of children's virtual play spaces, a case study method was employed to collect in-depth narratives of student identity construction in online and offline instances. Research questions were posed pertaining to children's digital literacy practice, such as: (1) What types of identities do young gamers construct while playing across sites? (2) In what ways does a child's playmaking from home and community converge in the virtual space. 
While a total of twenty children were interviewed over a period of three years, this article focuses on three children in particular, all ten years of age, in order to show how they enact different identity stances fluidly across different play spaces. The case study method is also appropriate for studying a 'bounded system,' that is, the thoughts and actions of participating students, as well as their online created identities, within a particular context across both real and virtual spaces (Stake, 2000). Case study research is particularized in that it focuses on a specific situation, event, program, or phenomenon. The case itself is important for what it reveals about the phenomenon of how these children evoke identity through play, and for what it might represent to teachers as ways in which children mediate meaning in their everyday lives. Engaging children in discussions around their play and learning provides for rich description of their learning. Consequently, a case study method enabled a fine-grained account of their literacy practices through game playing.

Participants' interviews were audio recorded with one of a team of three researchers, while playing online, during focus group interviews, and during individual interviews. Accurate transcription and appropriate interpretations of the participants' responses was made possible through captured game play on the screen using video recording with Camtasia, and through Jing.

Because of the complex blending of multimodal data elements, we used a digital visual literacy analysis method devised by Hull and Katz (2006) of developing a "pictorial and textual representation of those elements" (p. 50) - that is, columns of the spoken words from the game play, juxtaposed with original written text, the images from digital play, and data from interviews, field notes and video recordings. This representation facilitated the "qualitative analysis of patterns" (p. 50). The analytic methods included thematic coding (Miles, 1994) and critical discourse analysis (Fairclough, 1995). Critical discourse analysis is useful in pinpointing the storied selves of children's gaming lives. It vividly illustrates children's "ways of interacting, ways of representing and ways of being" (Rogers \& Elias, 2012 , p. 260). The data was read and coded for major themes such as types of gamer constructed identities and sub-themes such as social, cultural and political discourses across data sources. In regards to the construction of identities of the participants, we were particularly interested in moments that might be interpreted as "turning points" (Bruner, 1994) in the representation of the children's constructed identities and/or the conceptual understanding identity of play across sites.

\section{Findings: Identities in Practice}

In the next section, I look at three participants, identical twins Jason and Ethan, and their classroom friend Jackson. All three boys enjoyed playing video games, and had game consoles and Nintendo DS 3 hand held devices at home. All of the boys were in the same fourth grade class, played together at recess time, and participated in the virtual world of Club Penguin. Although they were not from the same neighborhood, they frequented the same afterschool program and had become avid users of Club Penguin. The use of Abrams' (2011) framework to consider the boys' identities as they move across online and offline play spaces in particular to demonstrate their "big I" and "little i" identity in practice (Leander, 2002), reveals how socio-emotional connections are part of their identities in gaming. This study utilizes characteristics of associative identity that we have re-purposed as descriptors for the data. In our close analysis of the boys' online and offline play, we looked at: (a) Purposeful behavior, (b) Motivation through the projective identity, (c) 
Fluidity between projective identity and performed identity, and (d) Leverage. In the next section, we introduce our participants and discuss our data in relation to Abrams' framework.

It is recess, and although the month of April, the $40 \mathrm{~km}$ per mile wind and cascading rain have made it feel like a cool Fall day, rather than the beginnings of spring. Mr. Sparks' (all names are pseudonyms) grade 4 class will not being going outside today, as they learn from the announcement made by the school principal. Disappointed with not being able to throw a few baskets during the mid morning break, Jason and Ethan (twin brothers) and Jackson, begin to chat about the latest scavenger hunt on Club Penguin. Jason handles his puffle (a small stuffed toy which has an online counterpart) like a basketball, throwing it in the air one minute, and slides it across the desk to his brother. Their discussion focuses on the Easter egg hunt on Club Penguin. They share strategies and clues how to find the hidden eggs and discuss the free stuff you can get for your penguin with a deluxe membership from Club Penguin.

Field Notes, April 2011

Purposeful behavior and emotional partnership - According to Abrams (2011), associative identity is the "association between one's purposeful behavior in the actual gaming space (performed identity) and one's emotional partnership with the virtual character (projective identity)" (p. 223). Throughout our classroom observations, we noted how these boys were quite connected to their penguins and, in particular, their puffles, which are stuffed toys in the real world, but pets in the virtual world of Club Penguin. Puffles can be adopted on the site and each color of the fuzzy round toys has a particular personality. While online, children must attend to the needs of the pet, such as playing their favorite activity, in order to keep them from running away. Children commonly drew from such primary discourses of their homes such as pet owners (Gee, 2009). In the classroom, children would often carry these toys around with them in backpacks or we would see them perched on their classroom desks. During recess, we would sometimes see children engaging in play on a makeshift table-top ice rink. They would use their puffles as hockey players in the game, using a Club Penguin coin token as a puck. On the desk, they would outline a hockey net in the form of a square made by masking tape. This was Jackson's favorite activity, one in which he was joined by Colin, another avid online player. Both of these boys played ice hockey on the weekends and shared, in an interview, that they played road hockey. During their puffle play during recess, one child would narrate the game like a hockey announcer: "Greenie Sid [Jackson's puffle is named after his favorite hockey player, Sidney Crosby] shoots and SCORES!" They would sometimes compete for Club Penguin privileges, such as being the first penguin in a sled race, or picking the server where they could meet online afterschool. In an interview with Jason and Ethan, they shared that, "Once we brought them [puffles] to Walmart, and we kept them in the car. They can run away, you know." In this exchange, we noted how Ethan describes the real world excursion but also refers to the tendency of the puffles to "run away," which is what happens in the virtual space if the pet is not properly cared for. These examples demonstrate the emotional connection between young gamers and their puffle toys and online pets. We observed emotional connections in how they choose to name, play with, and care for their puffles. The associative identities of 
these children, both individually and as a group, involve a strong emotional connection with their puffle pets both online and offline. The identities they embody, as a result, move fluidly through the play narratives the children share. The experiences the boys share are embodied practices. These embodied practices connect them to their virtual characters as both players and pet owners.

Motivation through the projective identity - Ethan and Jackson played in a very competitive manner with others, and for themselves, on the site. Abrams (2011) notes that the associative identity also accounts for "how a gamers' behavior is motivated by a connection to virtual stimuli and a real gaming environment" (p. 223). Ethan would compete in games such as 'Bean counters' where his penguin could earn coins at the coffee shop by catching bags of coffee, or Mancala which is an online board game in which penguins can participate, based on strategy and memory. His motivation for play was to win costumes for his penguin, such as the coveted knight costume. Ethan also suggested ways that activities on the site could be enhanced so that the player could play with his puffle like a toy pet at home, saying: "It would be cool if you could dress your puffle up in little clothes, right?!" Ethan spent a lot of time caring for his puffles. Considered a bit of a joker in the class, and identified as having a great sense of humor by his teacher, he arrived one day to tell me he had posted a joke on Club Penguin. He felt good about it, and the teacher showed everyone in class. We see how the associative I/identity is "helpful in explaining the performed behavior that is a response to virtual stimuli and is directed towards others" (Abram, 2011, p. 236).

Fluidity between projective Identity and performed identity - Abrams (2011) noted the importance of the "association between the performed and the projective identity - real world ways of being that are tied to [a gamer's] on screen Discourses and practices" (p.233). For the boys, the connection between these two spheres was very fluid. Jackson shared on the site that puffles are "like your dog or my cat [gesturing to himself as an owner of a cat], and you have to take care of them by feeding them. Like, your puffle looks sad when he is hungry, and in order to take the puffles for a walk, you would have to feed them first." Jason agreed and shared, "Yeah. [Then, pointing to his red puffle on the screen, he continued] ... wouldn't let me walk him, 'cause you can't walk them if they're hungry." In this example, we see how the children's connections as pet owners in the game extend beyond the online world, as their associated identities evoke the big I- identity discourses of a pet owner on the site. They take their obligation - to feed their pet and then prepare to take them for a walkvery seriously. Therefore, we see how Jackson materializes his virtual identity through the multimodal choices he makes about what to feed his pet, and how to play and care for his pet. He uses these actions to show others his ability to be apart of the pet owner's discourse, an aspect of his big I- identity. Another discussion took place in relation to the type of puffle the children each owned. Ethan, in speaking about his projected identity as a disco dancer, shared that one of his favorite things to do was to go to the club penguin costume parties and dance at the virtual club, where the music and floor lights create, in his words "a vibe in the room." In this example, we see Ethan's performed and projective identities coming together. His I/identity shows that he can distinguish a different way of being or "dancing" in Club Penguin. This is unlike the expectations in the real world where "everyone dances the same so you don't get made fun of," which according to the boys in the class was a regular occurrence at the school dances. In Ethan's discussion, we see how the 
associative I/identity "helps to articulate and define how feeling connected to the virtual character extends beyond the scope of the game" (Abrams, 2011, p. 233).

Leverage - Abrams (2011) discusses how associative identity also involves "responding to a virtual stimuli in an effort to achieve social and emotional gains related to performed identity" (p. 235). The socialization gained through multimodal features such as chatting with penguins at the town centre or serving coffee and making pizza with other penguins, were online activities that increased a gamer's chances of getting assistance from other learners. This type of collaborative learning provided leverage for Ethan to be successful in his games, and the sharing of information among the three boys was important to all of them. Ethan said, "Well, sometimes, if I, like, complete a game or something, if he [Jason] doesn't know how, then I'll show him how." Ethan also added that "Yeah, he [Jason] went through all this trouble to try to do it, and then I showed him that I found a short cut, and he got really mad." Competitive play was quite common among the boys. Jackson would often be the first to complete a mission and would often share his game play with the others in the morning upon arrival in the class.

Leveraging one's identity as a strategic gamer is another reason why gamers adopt a virtual identity. Although the brothers did not lack for offline friends, Ethan was cognizant of the fact he could leverage his play with others by having a deluxe account, which gave access to more games and virtual possessions, which his friends would view in his penguin's online igloo. He shared how friendships were fluid for him across online and offline spaces: "because if you're not online, and you're in school or something, you can still show your friends what your penguin looks like."

Through their virtual identities, gamers can accumulate respect and a following from other gamers on the site. This might have influenced Ethan to ensure that the clothes his puffles wear are acquired through competition, whereas his brother Jason buys his using the game's virtual currency. Ethan noted that his efforts give him a sense of achievement and said: "It shows you actually completed something." In a later interview, Ethan emphasized this point again, drawing attention to the difference between his efforts and his brother's, pointing out that his puffles' decorations allowed him to "show everyone that [he] completed that." Ethan expressed his own understanding of leverage in this way: "I like completing stuff to earn suits and medals and stuff." Ethan made a concerted effort to signal his identity as an achieved gamer, as confirmed by the following statement, which he offered with some contempt: "like anyone could just buy it [the custom materials] if you're a member." This favors Rowsell and Abram's (2011) assertion that "specific to individuals are the modes and practices that they choose for signaling subjectivities" (p. 3). Lacking the expensive membership, Ethan used strategic play, instead, to establish his identity.

Online spaces also give gamers the opportunity to create a space of equity that they can claim as their own. Being twin brothers, it could be difficult for Jason and Ethan to create such spaces in their offline identity. They have the same hobbies (hockey, basketball and reading the same book series, Big Nate and Diary of a Wimpy Kid). Ethan, in particular, felt the need to recognize the differences in their cognitive and subjective I/identities. He also tried to distinguish his online penguin identity from his brother by noting that "Some people can't tell us apart and that gets really annoying . . . because we both have different likes ... mine is more like clothes that you get from earning them. Jason usually has ones you buy from the shop." This statement speaks to the use of the associative identity as "it 
hinges on the inhabitation of Discourses and the realization of social and/or personal reward" (Abrams, 2011, p 236).

\section{Implications for Education}

In many ways, teachers will increasingly have to see past the idea that children's immersion in virtual spaces are a simplistic extension of their current play spaces, such as the after-school centre or the classroom. Abrams (2011) has posited that through association with the virtual character, gamers become more motivated to engage in online activity. This engagement is fuelled by the fact that, like offline play, students build social leverage from playing online. They are building their "big I" identity, which Rowsell and Abrams (2011) defined as "ways of acting, interacting, feeling, believing, valuing with other people and with various sorts of characteristics objects, symbols, tools and technologies" (p. 3). Consequently, educators are encouraged to look beyond the common tendency to see virtual immersion as a leisure activity and view it as "identity in practice" (Leander, 2002). In this study, the teachers thought of Club Penguin as the lunchtime social club, even though many times the data was collected during a classroom period designated for the play of Club Penguin. The teachers saw the virtual play as being of primary importance in the instruction around socialization. In this school community, parents and teachers were concerned with online bullying and the question of how to teach children to be good digital citizens. The idea that the site could be used for identity and literacy development was considered only as a way to connect to children's interests. Through the dispersion of specialist, general, and off-site knowledge, a virtual space "encourages and enables people to gain both individual knowledge and to learn to use and contribute to distributive knowledge" (Gee \& Hayes, 2010, p. 110). The boys' engagement with Club Penguin also offered great classroom potential for developing leadership skills and multiple literacies with the boys. Ethan shared strategies and clues on how to complete the site's secret agent missions, while Jason shared how to care for pets, and Jackson prided himself on knowing how to play games and purchase items for one's penguin's igloo.

Consequently, from the classroom perspective and based on the analysis provided, 'Identity' can be rethought. This framework demonstrates that the children's investment in their fluid Identities engages many different literacies; for example, both Jason and Ethan used problem solving skills and collaborative learning. Rowsell and Abrams (2011) noted that Identities entail cognitive changes that "we share and subjective changes that make us distinct" (p. 4). For Ethan, the use of effective problem solving skills were essential to attaining coins used to upgrade his igloo and purchase penguin costumes, both of which were important for his online identity. Moreover, collaborative learning also assisted the boys to "creatively and meaningfully improvise" (Rowsell \& Abrams, 2011, p. 6). Some of these skills are also similar to those used in classroom inquiry groups of mathematics and computer science; however, Gee (2007) and Gee and Hayes (2010) state that this form of creative exercise is grossly lacking in many schools today.

Additionally, Gee and Hayes (2011) explained that in many online spaces like Club Penguin the opportunity to learn as one plays is a powerful engagement for the children. They use the term 'passionate affinity groups' to describe groups in which people "relate to each other primarily in terms of common interests, endeavors, goals or practices-defined around shared passion" (Gee \& Hayes, 2011, p. 107). These groups provide fluid interactions between people who are acquainted to one another in their real world identity as 
well as people from different races, ages and localities who meet online exclusively. Brothers Jason and Ethan both shared characteristics of affinity groups. They found others in the class such as Jackson to discuss Club Penguin activities. Early in the observations, we noted that children who did not usually play with each other had, through the exigencies of the game, found another space to extend relationships and play together outside of the classroom and afterschool. By becoming players, the brothers accessed and shared many more social, cultural and political leverages. The beauty of the development of an associative identity through interaction with the virtual character is that it contributes to gamers' ability to "achieve social and emotional gains related to performed identity" (Abrams, 2011, p.235). With varying degrees of success, Ethan and Jason were able to achieve such social and emotional gains. They interacted with their friends both online and offline, developed a reputation for themselves as accomplished gamers, and transferred aspects of their cultural practice through play and ownership of puffles which signaled their virtual identities. For other children, such as Jackson, who struggled with offline interactions in the classroom, his virtual identity helped him to realize "social and/or personal reward[s]" (Abrams. 2011, p. 236). His classroom teacher was pleased that Jackson had made new friends as a result of the project, and felt his newly developed friendships helped him with peer collaborative projects in social studies and language arts. Nevertheless, as highlighted in the study, many children found the site to be only about purchasing and playing games. Although Gee and Hayes (2010) advocated for the use of online spaces and stimulation games as an avenue for "people to put digital tools to use to develop shared passions, which transform their skills, relationships and identities," there is a concern that online spaces and stimulation games also stagnate the imaginative play of children, which is needed to encourage more diverse and critical thinking skills. In addressing this concern, teachers and care-givers are encouraged to cultivate students' critical thinking through discussion of the relevant social, political and cultural ramifications of engagement in on screen-play.

\section{Conclusion}

Virtual worlds for early learners are growing at an astounding rate. It has been reported that there are more than 150 virtual worlds, either operating or in development, aimed at children and young people less than 18 years of age. These sites have around 355 million registered users under the age of 10 and 802 million aged ten to fifteen (K- Zero, 2012).

In our observations, we noted that popular culture influences the lives of these children, invested in toys and creative play. The children were driven by a consumer ethos, which impacts the creativity and choices the children would make. Like many virtual playworlds, Disney's Club Penguin is tied to the purchase of toys, films and books. Consequently, the identities the gamers create within these worlds are an enactment of gamers' identities, which Rowsell and Abrams (2011) explained, "cannot be reified into a single entity" (p. 5). Nor can educators ignore the consumerist ethos these games subtly impose on the gamers' identity construction. The diversity of such identities for children need to be seen as immersive, calling upon teachers to connect and to recognize that fluidity of such spaces as a needed part of everyday curriculum. Discussions, shared with teachers, can clarify not only how these types of gaming activities reveal an embodied experience for children and the "purposeful performance of a socially situated I/identity" (Abrams, 2011, p. 226) but also reinforce the potential value of such experiences. Gee and Hayes (2010) 
supported this by noting that the creation of passionate affinity groups (interest driven groups created through shared passion) in virtual worlds, such as Club Penguin, gives students ample opportunity for "transfer of a great many skills from this group work to other more school-like and workplace-like settings" (p. 182). In our study in a school, we noted that teachers were receptive to Club Penguin, acknowledging it as a play-space in which children could develop friendship and citizenship skills. Although the teachers were receptive to using the space for this purpose, they found it difficult to see that virtual worlds such as Club Penguin are immersive spaces where children engage in a plurality of activities and literacies that draw from many aspects of their lives, including classroom learning. The shifting and fluid identity and affinity groups, which were being created and leveraged within these spaces, were largely indiscernible to the children's educators. As society begins to see a greater increase in mobile technologies, there must be consideration of how these types of engagements will augment children's identity construction and affect children's literacies.

\section{References}

Abrams, S. (2011). Association through action: Identity development in real and virtual video game environments. National Society for the Study of Education, 110(1), 220-243.

Apperley, T. (2010). Gaming Rhythms: Play and Counterplay from the Situated and the Global. Amsterdam: Institute of Network Cultures.

Barton, D., \& Hamilton, M. (1998). Local literacies: Reading and writing in one community. London, UK: Routledge

Black, R. W. (2010). The language of Webkinz: Early childhood literacy in an online virtual world. Digital Culture \& Education, 2(1), 7-24.

Blanchard, J., \& Moore, T. (2010). The digital world of young children: Impact on emergent literacy. Retrieved from http://www.pearsonfoundation.org/downloads/EmergentLiteracy-WhitePaper.pdf

Bruner, J. (1994). The remembered self. In U. Neisser \& R. Fivush (Eds.), The Remembering Self: Construction and Agency in Self Narrative (pp. 41-54). Cambridge, UK: Cambridge University Press.

Burke, A. (2010). Ready to Learn: Using Play to Build Literacy skills in Young Learners. Markham Ontario: Pembroke Publishing.

Burke, A. (2013). Stardolls in the Virtual Playground. In A. Burke \& J Marsh (Eds.) Children's Virtual Playgrounds: Culture, Learning and Participation. New York, NY: Peter Lang (forthcoming).

Burke, A. \& Marsh, J. (2009) (Eds.) Children's Virtual Playworlds: Culture. Learning and Participation. New York, NY: Peter Lang (forthcoming).

Carrington, V. (2003). 'I'm in a bad mood. Let's go shopping': Interactive dolls, consumer culture and a 'glocalized' model of literacy. Journal of Early Childhood Literature, 3 (1), 83-98. doi: 10.1177/14687984030031004.

Carrington, V., \& Hodgetts, K. (2010). Literacy-lite in "BarbieGirls"[TM]. British Journal of Sociology of Education, 31(6), 671-682.

Consalvo, Mia (2003). Zelda 64 and video game fans: A walkthrough of games, intertextuality, and narrative. Television New Media, 4(321), 321-334.

Cope, B., \& Kalantzis, M. (Eds.). (2000). Multiliteracies: Literacy learning and the design of social futures. London, UK: Routledge. 
Common Sense Media. (2011). Zero to eight: Children's media use in America. [White Paper]. Retrieved from http://www.commonsensemedia.org/sites/default/files/research/zerotoeightfinal20 11.pdf

Cowan, J. (2010). Webkinz, blogs, and avatars: Lesson from young adolescents. In D.E. Alverman (Ed.), Adolescents' online literacies: Connecting classrooms, digital media and popular culture (pp. 27-49). New York, NY: Peter Lang.

Dowdall, C. (2009). Impressions, improvisations and compositions: Reframing children's text production in social network sites. Literacy, 43(2), 91-99. doi: 10.1111/j.1741-4369.2009.00521.x

Erickson, F. (1984). What makes school ethnography 'ethnographic'? Anthropology and Education Quarterly, 15(1), 51-66.

Gee, J.P. (1994). First language acquisition as a guide for theories of learning and pedagogy. Linguistics and Education, 6(4), 331-54.

Gee, J.P. (1996). Social linguistics and literacies: Ideology in discourses (2nd ed.). London, UK: Falmer Press.

Gee, J.P. (2001). Reading as situated language: A sociocognitive perspective. Journal of Adolescent and Adult Literacy, 44(8), 714-25.

Gee, J. P. (2004). Situated language and learning: A critique of traditional schooling. New York, NY: Routledge.

Gee, J.P. (2007). What video games have to teach us about learning and literacy. New York, NY: Palgrave.

Gee, J.P. (2008). Learning and games. In K. Salen (Ed.), The ecology of games. Connecting youth, games, and learning (pp. 21-40). Cambridge, MA: The MIT Press.

Gee, J.P. (2009). Language and discourses: Meaning is in the game. Retrieved from http://www.jamespaulgee.com/sites/default/files/pub/Language $\% 20$ and $\%$ 20Discourses.pdf.

Gee, J.P., \& Hayes, E.R. (2010). Women and gaming: The sims and 21 st century learning. Hampshire, UK: Palgrave Macmillian.

Gee, J.P., \& Hayes, E.R. (2011). Language and learning in the digital age. London/New York: Routledge.

Fairclough, N. (1995). Critical discourse analysis: The critical study of language.

London, UK: London

Hoppe, M.J., Wells, E.A., Morrison, D.M., Gillmore, M.R., \& Wilsdon, A. (1995). Using focus groups to discuss sensitive topics with children, Evaluation Review, 19(1), $102-114$.

Hull, G.A., \& Katz, M.L. (2006). Crafting an agentive self: Case studies of digital Storytelling. Research in the Teaching of English, 41(1), 43-81.

Jenkins, H. (2005). Getting into the game. The Adolescent Learner, 62(7), 48-51. Retrieved from http://mgicollaboration.pbworks.com/f/JenkinsGettingIntotheGame.pdf

Jewitt, C. (2009). An introduction to multimodality. In C. Jewitt (Ed.), The Routledge handbook multimodal analysis (pp. 14-27). New York, NY: Routledge.

Jewitt, C., \& Kress, G. (Eds.). (2003). Multimodal literacy. New York, NY: Peter Lang. k- Zero(2012). Survey,2012.http://www.kzero.co.uk.com. Retrieved February 16, 2013. 
Knobel, M., \& Lankshear, C. (2003). Researching Young Children's Out of School Practices. In N. Hall, J. Larson \& Marsh, J. (2003). Handbook of early childhood literacy (pp.51-66). London, UK: Sage.

Kress, G. (2003). Literacy in the new media age. New York, NY: Routledge.

Kress, G., \& Van Leeuwen T. (2001). Multimodal discourse: The modes and media of contemporary communication. New York, NY: Oxford University Press.

Lankshear. C., \& Knobel, M. (2006). New literacies: Everyday practices and classroom learning (2nd ed.). Berkshire, UK: Open University Press.

Lauwaert, M. (2009). The place of play: Toys and digital cultures. Amsterdam, The Netherlands: Amsterdam University Press.

Leander, K. (2002). Locating Latanya: The Situated Production of identity artifacts in classroom interaction. Research in the Teaching of English, 37, 198-250.

Leander, K., \& Frank, A. (2006). The aesthetic production and distribution of image/subjects among online youth. E-Learning, 3(2), 185-206.

Marsh, J. (2009). Countering chaos in Club Penguin: Young children's use of literacy. Paper presented at the British Educational Research Association Conference, Manchester, UK.

McClay, J.K. (2002). Hidden Treasure, New Genres, New Media and Teaching Writing. English in Education, 36(1) pp. 43-52.

Merriam, S.B. (1998). Qualitative research case study application in education. San Francisco, CA: Jossey Bass.

Miles, M. (1994). Qualitative data analysis: An expanded sourcebook. Thousand Oaks, CA: Sage

Moje, E.B., \& Luke, A. (2009). Literacy and identity: Examining the metaphors in history and contemporary research. Reading Research Quarterly, 44(4), 415-437.

New London Group. (1996). A pedagogy of multiliteracies: Designing social futures. Harvard Educational Review, 66(1), 60-92.

Marsh, J. (2010). Young children's play in online virtual worlds. Journal of Early Childhood Research, 8(1), pp. 23-38.

Ofcom. (2011). UK Children's Media Literacy. Retrieved June 2011 from http://stakeholders.ofcom.org.uk/market-data-research/medialiteracy/archive/medlitpub/medlitpubrss/ukchildrensml/

Rogers, R., \& Elias, M. (2012). Storied selves: A critical discourse analysis of young Children's literate identifications. Journal of Early Childhood Literacy,12(2),259292.

Rowsell, J., \& Abrams, S. (2011). (Re)conceptualizing I/identity: An introduction. National Society for the Study of Education, 110(1), 1-6.

Rowsell, J. \& Burke, A. (2009). Reading by Design: Two Case studies of Digital reading practices. Journal of Adult and Adolescent Literacy. 53(2) 106-118.

Stake, R. (1995). The art of case study research. Thousand Oaks, CA: Sage.

Stake, R. (2000). Case studies. In N. Denzin \& Y. Lincoln (Eds.), Handbook of qualitative research (pp.435-454). Thousand Oaks, CA: Sage Publications.

Stein, P. (2008). Multimodal instructional practices. In J. Coiro, M. Knobel, C. Lankshear \& D.J. Leu (Eds.), Handbook of research on new literacies (pp.871-898). New York, NY: Lawrence Erlbaum Associates.

Street, B. (1993). The new literacy studies: Guest editorial. Journal of Research in 
Reading, 16(2), 81-97.

Street, B. (1995). Social literacies: Critical approaches to literacy in development, ethnography and education. London, UK: Longman.

Turkle, S. (2011). Alone Together New York: Basic Books

Vygotsky, L. (1978). Mind in society: The development of psychological processes. Cambridge, MA: Harvard Press.

Wells, G. (1999). Dialogic inquiry: Towards a sociocultural practice and theory of education. New York, NY: Cambridge University Press.

Zevenbergen, R. (2007). Digital natives come to preschool: Implications for early childhood practice. Contemporary Issues in Early Childhood, 8(1), 19-29.

\section{Author Biography}

Anne Burke is an Associate Professor in Literacy Education and Early Learning at Memorial University. She researches and writes about the evolving role of play in children's digital and immersive worlds, multimodality, the growth of social media in children's early learning engagements. Much of her recent SSHRC research, conducted in Canadian classrooms has focused on play and virtual worlds developed specifically for children, and how children's interactions with these virtual worlds affects their reading, writing, authoring and social presence in and out of school. Recent book titles include Play to Learn, Assessing New Literacies: Perspectives from the Classroom (co-edited with Hammett). 